\title{
Aneurysmal Parent Artery-Specific Inflow Conditions for Complete and Incomplete Circle of Willis Configurations
}

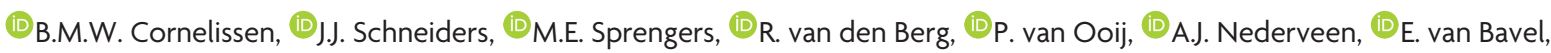

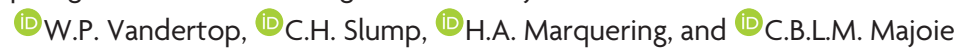

\begin{abstract}
BACKGROUND AND PURPOSE: Hemodynamics are thought to play a role in intracranial aneurysm growth and rupture. Computational fluid dynamics is frequently performed to assess intra-aneurysmal hemodynamics, using generalized flow waveforms of healthy volunteers as inflow boundary conditions. The purpose of this study was to assess differences in inflow conditions for different aneurysmal parent artery locations and variations of circle of Willis configurations.
\end{abstract}

MATERIALS AND METHODS: In a series of 96 patients with 103 aneurysms, velocity measurements were acquired using 2D phase-contrast MR imaging perpendicular to the aneurysmal parent arteries in the circle of Willis. Circle of Willis configurations were inspected for variations using multiple overlapping thin-slab-acquisition MRAs. Flow rates, velocity magnitudes, and pulsatility indices were calculated for each parent artery location in subgroups of complete and incomplete circle of Willis configurations.

RESULTS: Flow rates, velocity magnitudes, and pulsatility indices were significantly different among aneurysmal parent arteries. Incomplete circle of Willis configurations were observed in $24 \%$ of the cases. Significantly lower basilar artery flow rates were observed in configurations with hypoplastic P1 segments. Significantly higher Al flow rates were observed in configurations with a hypoplastic contralateral Al segment.

CONCLUSIONS: Inflow conditions vary substantially between aneurysmal parent arteries and circle of Willis configurations. We have created a collection of parent artery-specific inflow conditions tailored to the patient-specific circle of Willis configuration that can be used in future computational fluid dynamics studies analyzing intra-aneurysmal hemodynamics.

ABBREVIATIONS: ACA = anterior cerebral artery; AcomA = anterior communicating artery; $\mathrm{BA}=$ basilar artery; CoW = circle of Willis; $\mathrm{PC}-\mathrm{MR}=$ phase-contrast MR imaging; PcomA = posterior communicating artery; $\mathrm{PI}=$ pulsatility index; $\mathrm{VA}=$ vertebral artery

$\mathbf{T}$ he incidence of an unruptured intracranial aneurysm in the general population is approximately $3 \% .{ }^{1}$ Most of these aneurysms are asymptomatic, and $50 \%-80 \%$ of all aneurysms do not rupture during the individual's lifetime. ${ }^{2}$ However, rupture results in subarachnoid hemorrhage, a devastating occurrence associated with high morbidity and fatality rates. ${ }^{2}$ In clinical prac-

Received October 23, 2017; accepted after revision January 31, 2018.

From the Departments of Radiology and Nuclear Medicine (B.M.W.C., J.J.S., M.E.S., R.v.d.B., P.v.O., A.J.N., H.A.M., C.B.L.M.M.), Biomedical Engineering and Physics (B.M.W.C., E.v.B., H.A.M.), and Neurosurgery (W.P.V.), Academic Medical Center, Amsterdam, the Netherlands; MIRA Institute for Biomedical Technology and Technical Medicine (B.M.W.C., C.H.S.), University of Twente, Enschede, the Netherlands; and Department of Radiology (J.J.S.), Erasmus MC University Medical Center, Rotterdam, the Netherlands.

Henk A. Maquering and Charles B.L.M. Majoie contributed equally to this work. This work was supported by a grant from the Stichting Toegepast Wetenschappelijk Instituut voor Neuromodulatie (TWIN), the Netherlands. The HEROICA study was supported by a grant from the Nuts-OHRA Foundation, the Netherlands.

Please address correspondence to Bart Cornelissen, Meibergdreef 9, 1105 AZ, Department of Biomedical Engineering and Physics, Academic Medical Center, Amsterdam, the Netherlands; e-mail: b.m.cornelissen@amc.nl tice, large size ( $\geq 7 \mathrm{~mm}$ ) and high-risk location (posterior circulation and communicating arteries) are most frequently used to identify aneurysms with a high risk of rupture. ${ }^{3}$ However, most aneurysms are $<7 \mathrm{~mm}$, and a proportion of these small aneurysms rupture, nevertheless. ${ }^{4}$ Therefore, many studies have been performed to identify additional risk factors for rupture to improve the management of unruptured intracranial aneurysms.

Besides morphologic parameters, intra-aneurysmal hemodynamics are thought to play a role in aneurysm formation, growth, and rupture. Therefore, hemodynamics are frequently assessed to search for differences between ruptured and unruptured aneurysms. ${ }^{5,6}$ To analyze hemodynamic properties, computational fluid dynamics are commonly used to simulate the blood flow in patientspecific aneurysm models. Computational fluid dynamics depend highly on boundary conditions such as geometry and inflow waveforms. ${ }^{7-9}$ Therefore, high-resolution $3 \mathrm{D}$ angiographic imaging and

Indicates article with supplemental on-line table.

http://dx.doi.org/10.3174/ajnr.A5602 

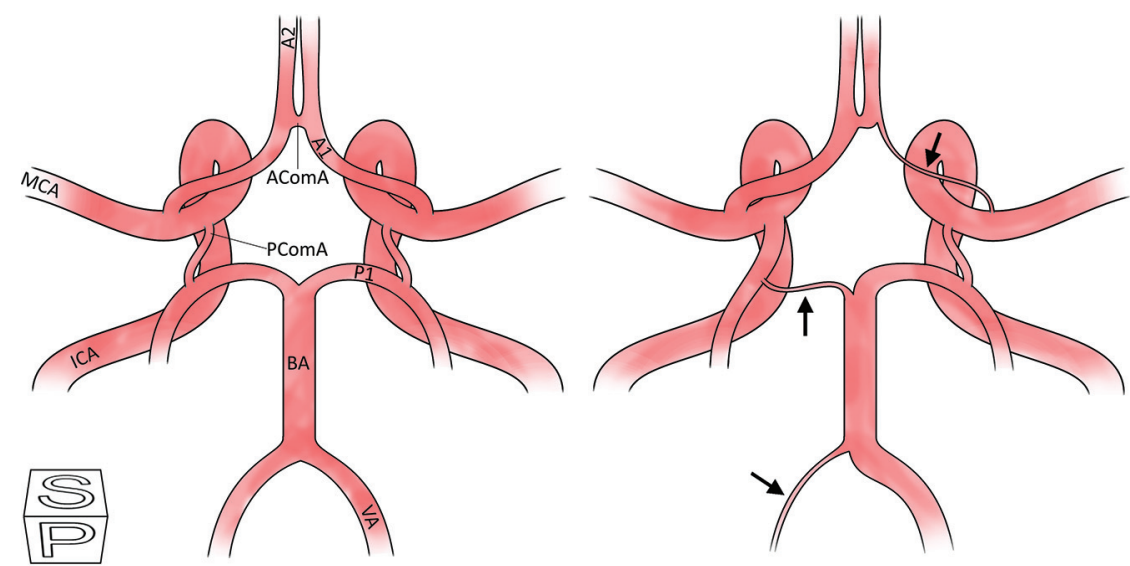

A

B

FIG 1. Schematic overview of 2 different CoW configurations. A, Textbook-type. $B$, Variant-type with hypoplastic $\mathrm{VA}, \mathrm{Pl}$, and $\mathrm{Al}$ segments, see arrows. $\mathrm{VA}$ and $\mathrm{Al}$ segments with diameters $\leq 50 \%$ compared with the contralateral side and Pl segments $<$ PcomA were defined as hypoplastic.

spaced cardiac phases. PC-MR imaging was performed before treatment for patients with unruptured aneurysms or at 6-month follow-up after endovascular treatment for cases with acutely ruptured aneurysms. A routine multiple overlapping thin-slab-acquisition MRA sequence with a scan resolution of $0.4 \times 0.4 \times 0.5$ $\mathrm{mm}$ was performed to visualize the aneurysm and was used to assess CoW configurations.

\section{Assessment of CoW Configurations}

Absence or hypoplasia of arterial components in the CoW was assessed by an experienced neuroradiologist (M.E.S.), using axial reconstructions and volumerenderings of the multiple overlapping thin-slab-acquisition MRA data. A1 and

patient-specific data of inflow velocities are needed. Because patientspecific velocity waveforms are rarely available, generalized velocity waveforms of healthy subjects are frequently used. ${ }^{10,11}$ However, intracranial flow velocities vary widely among subjects. ${ }^{12,13}$ A previous study showed that generalized waveforms result in different hemodynamic characteristics, compared with patient-specific velocity waveforms. ${ }^{14}$ A similar heterogeneity in flow patterns is expected among variations in location and configuration of the circle of Willis (CoW) ${ }^{15}$ This variety of aneurysmal inflow conditions in different aneurysmal parent arteries, considering anatomic variations in the CoW, is insufficiently studied. In this study, we present locationspecific aneurysmal inflow waveforms for arteries in the CoW and determine the influence of $\mathrm{CoW}$ variations on local flow conditions.

\section{MATERIALS AND METHODS \\ Patient Selection}

All patients treated in the Academic Medical Center Amsterdam for a ruptured or unruptured aneurysm from January 2009 to October 2011 were invited to participate in the Hemodynamics for Rupture Risk Assessment of Intracranial Aneurysms (HEROICA) study. ${ }^{16}$ The HEROICA study assessed the additional value of hemodynamics in discriminating ruptured and unruptured aneurysms and was approved by the institutional review board. Written informed consent was obtained from all patients. To assess the variation of inflow in these aneurysms, we included all patients with sufficient quality phase-contrast MR imaging (PC-MR) in the HEROICA dataset.

\section{MR Imaging}

MR imaging was performed at 3T (Intera; Philips Healthcare, Best, the Netherlands). 2D PC-MR imaging was performed for velocity measurements perpendicular to the aneurysmal parent arteries. These included the basilar artery (BA), vertebral artery (VA), internal carotid artery, middle cerebral artery, and the A1 and A2 segments of the anterior cerebral artery (ACA). Heart rate monitoring was performed by electrocardiography or by a peripheral pulse unit and was used for cardiac triggering and heart rate calculations. PC-MR imaging resolution was $0.63 \times 0.63 \times 3 \mathrm{~mm}$. Velocity-encoding was $70-$ $100 \mathrm{~cm} / \mathrm{s}$. Velocity measurements were acquired in 23-36 uniformly
VA hypoplasia were defined as diameters of $\leq 50 \%$ compared with the contralateral side. ${ }^{17,18}$ Hypoplasia of the P1 segment of the posterior cerebral artery was defined as a diameter smaller than that of the feeding posterior communicating artery (PcomA). ${ }^{19,20}$ Hypoplasia of the PcomA and anterior communicating artery (AcomA) was defined as diameters of $\leq 0.8 \mathrm{~mm} .{ }^{21}$ A textbooktype $\mathrm{CoW}$ configuration and a variant-type CoW configuration with anatomic variations of the VA, P1, and A1 are schematically presented in Fig 1.

CoW configurations were dichotomized into perianeurysmal complete and incomplete groups. Configurations were considered incomplete in case the vascular morphology near the aneurysm presented anatomic variants that were expected to alter local flow rates. For ICA and MCA parent artery locations, configurations with hypoplastic ipsilateral P1 and/or contralateral A1 segments were considered incomplete. For A1 measurement cases, configurations with hypoplastic ipsi- or contralateral A1 segments were considered incomplete. For A2 parent artery locations, azygos ACA or ACA trifurcation configurations were considered incomplete. For the VA, configurations with hypoplastic ipsi- or contralateral VA segments were considered incomplete. For BA cases, 1- or 2-sided hypoplastic P1 segments were considered incomplete configurations.

\section{Flow Parameters}

To define the inflow region of the parent artery, we extracted a contour for each cardiac phase using a level-set evolution algorithm $^{22}$ in the PC-MR magnitude images. Due to arterial pulsatility, the inflow region could have varied between cardiac phases. Spatial-averaged velocity waveforms were calculated for every patient by dividing the sum of the velocity magnitudes in each cardiac phase by the time-averaged inflow area. Flow waveforms were calculated by multiplying the sum of through-slice velocity components by the area of the inflow region for each cardiac phase. High-frequency components in the flow and velocity waveforms were considered noise and therefore suppressed using an eighth-order low-pass Butterworth filter ${ }^{23}$ with a half-power frequency of $0.32 \mathrm{~Hz}$. Using the flow- and velocity-waveforms, we 
calculated temporally averaged flow rates and mean velocity magnitudes. In addition, the pulsatility index (PI) was calculated to quantify the pulsatile character of the flow waveforms. The PI was defined as the ratio of flow variation to the average flow during a cardiac cycle (Fig 2). ${ }^{24}$ Parent artery-specific flow parameters were calculated for subgroups with perianeurysmal complete and incomplete CoW configurations.

\section{Location-Representative Waveforms}

Eleven features were automatically extracted for each waveform (Fig 2). The waveform was characterized by the diastolic minimum (M) and peak systole (P). ${ }^{25}$ Additional systolic features were extracted for $25 \%, 50 \%$, and $75 \%$ of the amplitude $\left(S_{1}, S_{2}, S_{3}\right)$. Diastolic features were extracted for $75 \%$ of the amplitude after systole $\left(D_{1}\right)$, half-maximum after systole $(H)$, and 4 uniformly in time-spaced features between $\mathrm{H}$ and the end of the cardiac cycle

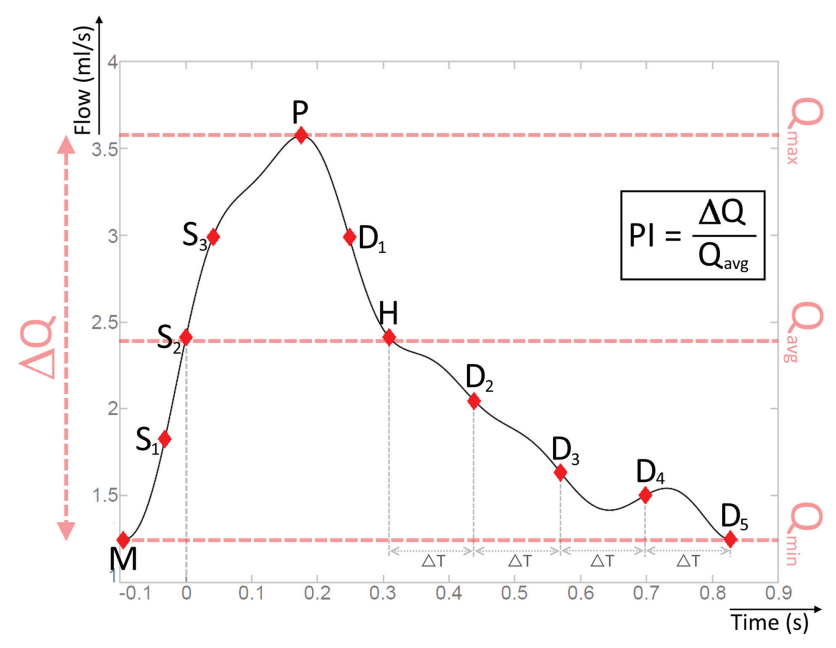

FIG 2. Automatic extraction of 11 waveform features and the PI. M: diastolic minimum. $\mathrm{S}_{1}-\mathrm{S}_{3}: 25,50$, and $75 \%$ of the amplitude before peak systole. P: peak systole. $D_{1}: 75 \%$ of the amplitude after peak systole. $\mathrm{H}$ : half-maximum after systole. $\mathrm{D}_{2}-\mathrm{D}_{5}$ : late diastolic features, equally spaced in time $(\triangle T)$. Feature $S_{2}$ was set to time $=0$ s.

Table 1: Prevalence of anatomic variants in the CoW

\begin{tabular}{lll}
\hline $\begin{array}{c}\text { CoW Configuration } \\
(\boldsymbol{n}=\mathbf{9 6})\end{array}$ & \multicolumn{1}{c}{$\begin{array}{c}\text { Absent/Hypoplastic } \\
\text { Vascular Components }\end{array}$} & $\%$ \\
\hline Textbook type & None & 10 \\
Variant anatomy & PcomA & 73 \\
& AcomA & 25 \\
& Pl & 24 \\
& VA & 21 \\
& Al & 16 \\
& Pl, VA, and/or Al combined & 46 \\
\hline
\end{tabular}

\begin{tabular}{llr}
$\begin{array}{l}\text { Table 2: Prevalence of perianeurysmal incomplete CoW configurations for each aneurysmal } \\
\text { parent artery location }\end{array}$ & \\
\hline $\begin{array}{l}\text { PC-MR Measurement } \\
\text { Location (Aneurysm } \\
\text { Location) }\end{array}$ & \multicolumn{1}{c}{ Incomplete Configuration } & No. \\
\hline ICA (ICA/PcomA) & Hypoplastic ipsilateral Pl and/or contralateral A1 & $7 / 30(23 \%)$ \\
MCA & Hypoplastic ipsilateral Pl and/or contralateral A1 & $6 / 30(20 \%)$ \\
Al (AcomA) & Hypoplastic contralateral Al & $7 / 28(25 \%)$ \\
A2 (pericallosal artery) & Azygos ACA & $1 / 4(25 \%)$ \\
VA & Hypoplastic ipsilateral VA & $1 / 2(50 \%)$ \\
BA & Hypoplastic Pl (1- or 2-sided) & $3 / 9(33 \%)$ \\
Total & & $25 / 103(24 \%)$ \\
\hline
\end{tabular}

$\left(D_{2}-D_{5}\right)$. Feature $S_{2}$ was set to time $=0$ seconds. Median feature points were calculated by taking the median flow amplitude at the median time point in the cardiac cycle. Similarly, the interquartile range (IQR) was calculated for each feature point. Location-representative waveforms were generated by cubic spline interpolation of the median feature points for aneurysmal parent arteries in complete and incomplete configurations. The slopes of the first and last feature points were set to zero.

\section{Statistical Analysis}

The Kruskal-Wallis test was performed to determine whether flow parameters were different between aneurysmal parent arteries. Subsequently, the Tukey honestly significant difference was performed to analyze differences between combinations of groups. MannWhitney $U$ tests were used to assess whether parent artery-specific flow parameters were different between complete and incomplete CoW configurations. In addition, mean velocity magnitudes and PIs were compared between anterior and posterior parent arteries. $P$ values $<.05$ indicated statistically significant differences.

\section{RESULTS}

A total of 96 patients (62 women) with 103 aneurysms (61 ruptured) were included in this study. The median patient age was 53 years (range, 27-76 years). Heart rates ranged between 51 and 109 beats per minute, with a mean of $69 \pm 10$ beats per minute. The prevalence of anatomic variants in the CoW is shown in Table 1. Only $10 \%$ of the patients had a textbook-type CoW configuration, and almost half of the CoW configurations presented with hypoplastic VA, A1, and/or P1 segments.

Table 2 shows the prevalence of perianeurysmal incomplete CoW configurations for each aneurysmal parent artery location. Configurations were incomplete in $24 \%$ of the cases. Figure 3 presents boxplots for aneurysmal parent artery-specific flow rates in complete and incomplete CoW configurations. Table 3 shows flow and velocity measures for aneurysmal parent arteries in complete and incomplete configurations. The Location-representative flow and velocity waveforms are shown in Figs 4 and 5, respectively, for aneurysmal parent arteries in perianeurysmal complete and incomplete CoW configurations. Group median (IQR) feature points are shown in the On-line Table.

Flow rates, velocity magnitudes, and PIs were significantly different among parent artery locations: $P<.001, P=.008$, and $P=$ .041 , respectively. VA flow rates were significantly lower compared with ICA flow rates. Furthermore, significantly lower mean velocity magnitudes were observed for the VA arteries compared with the MCA arteries. No statistically significant differences in PIs were found in pair-wise comparisons among parent artery locations.

BA flow rates were significantly lower for subgroups with 1 or 2 hypoplastic P1 segments. Significantly higher A1 flow rates were observed in configurations with a hypoplastic contralateral A1 segment.

Cases of aneurysmal parent arteries in the posterior circulation showed sig- 
nificantly higher PIs $(P=.017)$ and lower mean velocity magnitudes $(P=.034)$ compared with parent arteries in the anterior circulation.

\section{DISCUSSION}

Our study presents location-specific flow rates and velocity magnitudes and shows significant differences among aneurysmal parent artery locations in the CoW. Hypoplastic VA, A1, or P1 segments were observed in almost half of our population. Higher flow rates were observed in A1 segments with an absent or hypoplastic contralateral A1, and lower flow rates for BAs with hypoplastic P1 segments.

Intracranial flow rates have been assessed in several previous PC-MR studies ${ }^{26,27}$ with relatively small study populations of healthy subjects. In these studies, flow rates were comparable with our findings; however, no information regarding anatomic variations in the CoW configurations was provided in these studies. Other studies investigated relationships between anatomic variations in the CoW and neurovascular diseases; however, no relations with aneurysmal inflow were assessed. The prevalence of VA, A1, and P1 hypoplasia in our study was similar to that reported previously. ${ }^{18,19,28}$ The cerebral blood flow distribution in different configurations of the CoW was assessed previously. ${ }^{29}$ In this study, decreased BA flow rates were observed in fetal-type posterior cerebral artery configurations, and increased ICA flow rates, in the ipsilateral fetal-type posterior cerebral artery and missing contralateral A1 configurations. Our study also showed significantly lower BA flow rates in hypoplastic P1 configurations, and a trend toward higher ICA flow rates in ipsilateral hypoplastic P1s and hypoplastic contralateral A1 configurations was seen. The relation between the CoW configuration and flow rates of the ICA and BA has also been studied in healthy volunteers; this study showed similar findings. ${ }^{15}$ However, A1 and P1 hypoplasia was only observed in $5 \%$ of the study population.

It has been shown that inflow variations of $<25 \%$ have little effect on flow characteristics in computational fluid dynamics simulations. ${ }^{30}$ Our study presents larger velocity and flow variations among parent artery locations and CoW configurations. Furthermore, in accordance with previously reported data, ${ }^{31}$ the interpatient variability of peak systolic flow measures was $>25 \%$. This finding suggests that those parameters should be taken into account in computational fluid dynamics calculations. $^{32}$

Our study has several limitations. The limited imaging resolution of the PC-MR image resulted in partial volume artifacts, which might have led to inaccurate delineations of inflow regions, resulting in inaccurate velocity magnitude calculations.

FIG 3. Boxplots for aneurysmal parent artery-specific flow rates in complete (left) and incomplete (right) CoW configurations. The asterisk indicates a statistically significant difference $(P<.05)$.

Table 3: Mean velocity magnitudes, flow rates, and PIs for aneurysmal parent arteries in complete and incomplete CoW configurations

\begin{tabular}{|c|c|c|c|c|c|c|c|}
\hline $\begin{array}{l}\text { Aneurysmal } \\
\text { Parent } \\
\text { Artery }\end{array}$ & $\begin{array}{c}\text { Perianeurysmal } \\
\text { CoW } \\
\text { Configuration }\end{array}$ & $\begin{array}{c}\text { Flow Rate } \\
\text { (mL/s) (Median) } \\
\text { (IQR) }\end{array}$ & $\begin{array}{c}P \\
\text { Value }\end{array}$ & $\begin{array}{l}\text { Mean Velocity } \\
\text { Magnitude (cm/s) } \\
\text { (Median) (IQR) }\end{array}$ & $\begin{array}{c}P \\
\text { Value }\end{array}$ & $\begin{array}{c}\text { PI } \\
\text { (Median) } \\
\text { (IQR) }\end{array}$ & $\begin{array}{c}P \\
\text { Value }\end{array}$ \\
\hline \multirow[t]{2}{*}{ ICA } & Complete & $3.60(3.03-4.84)$ & .16 & $36.3(29.8-46.2)$ & 1.00 & $0.91(0.75-1.12)$ & .49 \\
\hline & Incomplete & $3.96(3.74-4.15)$ & & $36.4(32.7-39.1)$ & & $0.98(0.87-1.18)$ & \\
\hline \multirow[t]{2}{*}{ MCA } & Complete & $2.48(1.86-2.97)$ & .15 & $44.6(35.4-49.5)$ & .19 & $0.80(0.66-0.94)$ & .42 \\
\hline & Incomplete & $1.98(1.78-2.25)$ & & $38.7(34.2-42.2)$ & & $0.95(0.74-0.97)$ & \\
\hline \multirow[t]{2}{*}{$\mathrm{Al}$} & Complete & $1.42(1.12-1.60)$ & $.01^{\mathrm{a}}$ & $34.2(29.5-38.7)$ & .52 & $0.78(0.69-1.06)$ & .49 \\
\hline & Incomplete & 1.88 (1.65-2.51) & & $37.9(29.5-45.3)$ & & $0.75(0.63-0.83)$ & \\
\hline \multirow[t]{2}{*}{$\mathrm{A} 2$} & Complete & $0.78(0.57-1.08)$ & .50 & $21.4(19.1-33.5)$ & 1.00 & $0.63(0.52-0.99)$ & .50 \\
\hline & Incomplete & 1.26 & & 35.2 & & 1.13 & \\
\hline \multirow[t]{2}{*}{ VA } & Complete & 1.90 & 1.00 & 19.1 & 1.00 & 1.11 & 1.00 \\
\hline & Incomplete & 0.99 & & 16.5 & & 1.20 & \\
\hline \multirow[t]{2}{*}{ BA } & Complete & $2.45(1.87-2.81)$ & $.02^{\mathrm{a}}$ & $36.0(31.3-42.8)$ & .17 & $1.00(0.86-1.06)$ & .71 \\
\hline & Incomplete & $0.88(0.78-1.26)$ & & $25.9(21.6-30.5)$ & & $1.05(0.98-1.19)$ & \\
\hline
\end{tabular}

${ }^{a}$ Indicates a statistically significant difference $(P<.05)$. 


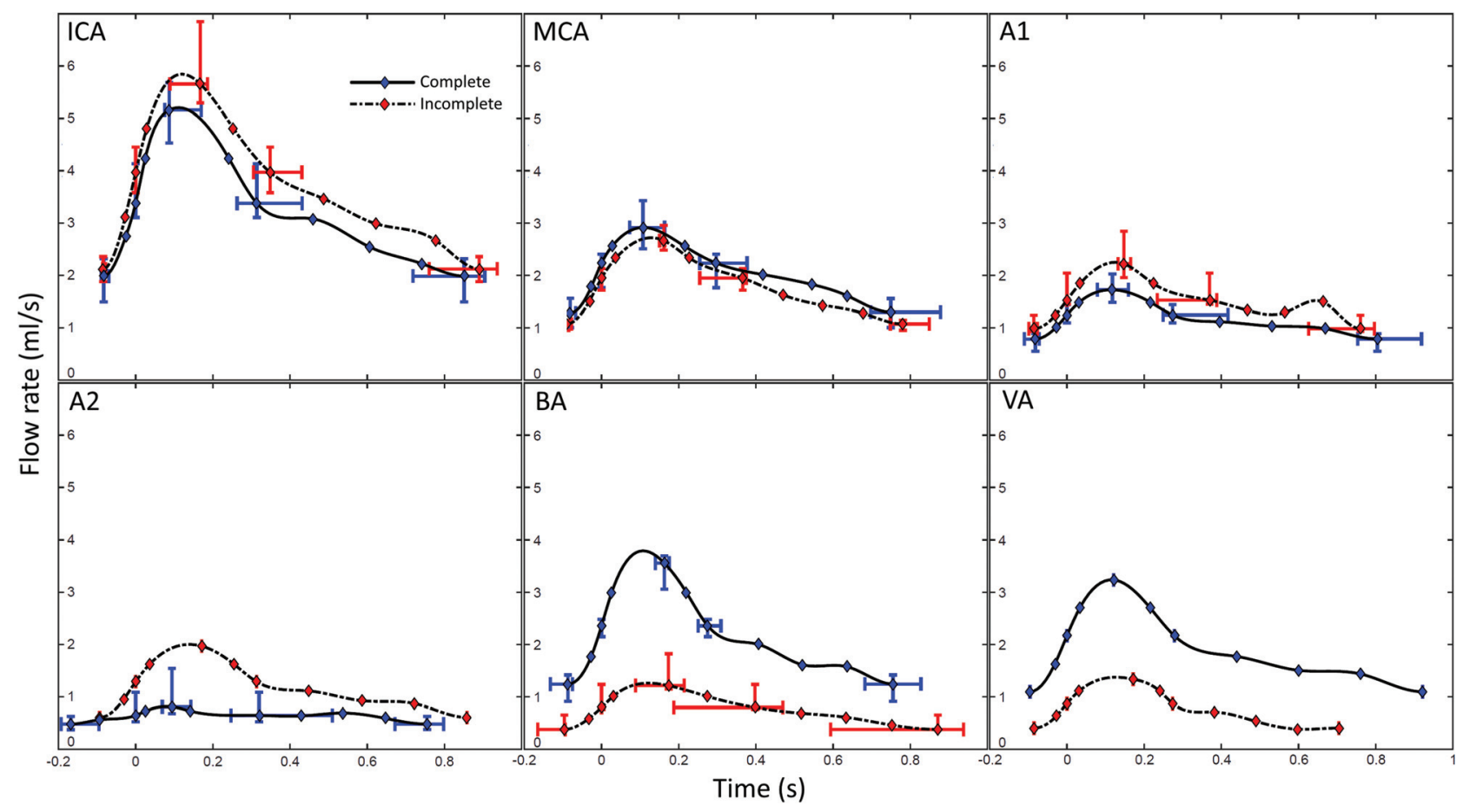

FIG 4. Location-representative flow waveforms for aneurysmal parent arteries in perianeurysmal complete (blue) and incomplete (red, dashed) CoW configurations. Interquartile ranges are presented for feature points $\mathrm{M}, \mathrm{S}_{2}, \mathrm{P}, \mathrm{H}$, and $\mathrm{D}_{6}$.

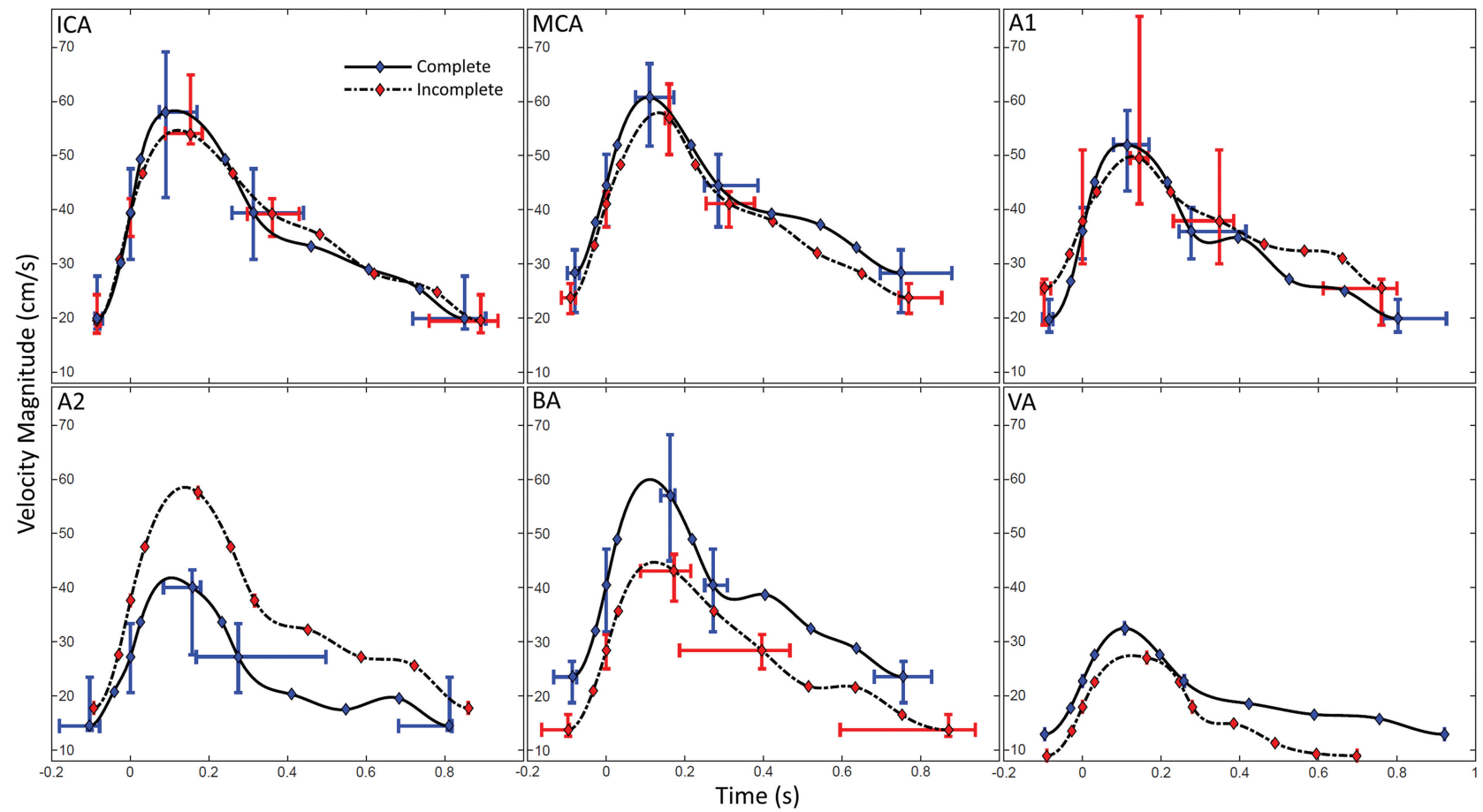

FIG 5. Location-representative velocity waveforms for aneurysmal parent arteries in perianeurysmal complete (blue) and incomplete (red, dashed) CoW configurations. Interquartile ranges are presented for feature points $M, S_{2}, P, H$, and $D_{6}$.

We used time-averaged cross-sectional areas of the PC-MRA imaging to calculate temporal velocity profiles, which might not agree with the areas of the 3D rotational angiography-derived vascular models used for computational fluid dynamics because of differences in imaging and segmentation methods. Furthermore, differences in velocity-encoding might have influenced the results, and the quality requirements for the PC-MR imaging might have resulted in a selec- tion bias. Another limitation of our study was the relatively small sample size. For VA and A2 cases, large differences in flow rates were observed between complete and incomplete configurations, but due to the small sample size, we could not determine whether this was a systematic deviation. Furthermore, low TOF intensities hindered the assessment of hypoplastic segments in some cases due to slow flow or coil artifacts. In addition, CoW assessment was performed by $1 \mathrm{ob}-$ 
server only, and comparison with previous results from the literature was hampered by the use of different definitions for hypoplasia of vascular segments.

\section{CONCLUSIONS}

There is variation in aneurysmal inflow conditions among parent arteries and CoW configurations. When patient-specific inflow waveforms are not available, we recommend using parent arteryspecific flow waveforms, tailored to the patient-specific CoW configuration to improve the accuracy of intra-aneurysmal hemodynamic simulations. We have made a collection available of flow and velocity waveforms that can be used in future computational fluid dynamics studies.

Disclosures: René van den Berg—UNRELATED: Consultancy: Codman Depuy Neurovascular, Comments: coil development, ${ }^{*}$ Henk A. Marquering-OTHER RELATIONSHIPS: cofounder and shareholder of Nico-lab. Charles B.L.M. Majoie-RELATED: Grant: TWIN Foundation*; UNRELATED: Grants/Grants Pending: Dutch Heart Foundation, Stryker. * ${ }^{*}$ Money paid to the institution.

\section{REFERENCES}

1. Vlak MH, Algra A, Brandenburg R, et al. Prevalence of unruptured intracranial aneurysms, with emphasis on sex, age, comorbidity, country, and time period: a systematic review and meta-analysis. Lancet Neurol 2011;10:626-36 CrossRef Medline

2. Brisman JL, Song JK, Newell DW. Cerebral aneurysms. N Engl J Med 2006;355:928-39 CrossRef Medline

3. Wiebers DO, Whisnant JP, Huston J 3rd, et al; International Study of Unruptured Intracranial Aneurysms Investigators. Unruptured intracranial aneurysms: natural history, clinical outcome, and risks of surgical and endovascular treatment. Lancet 2003;362:103-10 CrossRef Medline

4. Morita A, Kirino T, Hashi K, et al; UCAS Japan Investigators. The natural course of unruptured cerebral aneurysms in a Japanese cohort. N Engl J Med 2012;366:2474-82 CrossRef Medline

5. Xiang J, Natarajan SK, Tremmel M, et al. Hemodynamic-morphologic discriminants for intracranial aneurysm rupture. Stroke 2011; 42:144-52 CrossRef Medline

6. Chien A, Sayre J. Morphologic and hemodynamic risk factors in ruptured aneurysms imaged before and after rupture. AJNR Am J Neuroradiol 2014;35:2130-35 CrossRef Medline

7. Valen-Sendstad K, Steinman DA. Mind the gap: impact of computational fluid dynamics solution strategy on prediction of intracranial aneurysm hemodynamics and rupture status indicators. $A J N R$ Am J Neuroradiol 2014;35:536-43 CrossRef Medline

8. Castro MA, Putman CM, Cebral JR. Computational fluid dynamics modeling of intracranial aneurysms: effects of parent artery segmentation on intra-aneurysmal hemodynamics. AJNR Am J Neuroradiol 2006;27:1703-09 Medline

9. Venugopal P, Valentino D, Schmitt H, et al. Sensitivity of patient-specific numerical simulation of cerebral aneurysm hemodynamics to inflow boundary conditions. J Neurosurg 2007;106:1051-60 CrossRef Medline

10. Cebral JR, Castro MA, Soto O, et al. Blood-flow models of the circle of Willis from magnetic resonance data. JEng Math 2003;47:369-86 CrossRef

11. Steinman DA, Milner JS, Norley CJ, et al. Image-based computational simulation of flow dynamics in a giant intracranial aneurysm. AJNR Am J Neuroradiol 2003;24:559-66 Medline

12. Stock KW, Wetzel SG, Lyrer PA, et al. Quantification of blood flow in the middle cerebral artery with phase-contrast MR imaging. Eur Radiol 2000;10:1795-800 CrossRef Medline

13. Oktar SO, Yücel C, Karaosmanoglu D, et al. Blood-flow volume quantification in internal carotid and vertebral arteries: comparison of 3 different ultrasound techniques with phase-contrast MR imaging. AJNR Am J Neuroradiol 2006;27:363-69 Medline
14. Jansen IG, Schneiders JJ, Potters WV, et al. Generalized versus patient-specific inflow boundary conditions in computational fluid dynamics simulations of cerebral aneurysmal hemodynamics. AJNR Am J Neuroradiol 2014;35:1543-48 CrossRef Medline

15. Tanaka H, Fujita N, Enoki T, et al. Relationship between variations in the circle of Willis and flow rates in internal carotid and basilar arteries determined by means of magnetic resonance imaging with semiautomated lumen segmentation: reference data from 125 healthy volunteers. AJNR Am J Neuroradiol 2006;27:1770-75 Medline

16. Schneiders JJ, Marquering HA, van Ooij $\mathrm{P}$, et al. Additional value of intra-aneurysmal hemodynamics in discriminating ruptured versus unruptured intracranial aneurysms. AJNR Am J Neuroradiol 2015;36:1920-26 CrossRef Medline

17. Kwak R, Niizuma H, Suzuki J. Hemodynamics in the anterior part of the circle of Willis in patients with intracranial aneurysms: a study by cerebral angiography. Tohoku J Exp Med 1980:69-73 Medline

18. Rinaldo L, McCutcheon BA, Murphy ME, et al. Relationship of A1 segment hypoplasia to anterior communicating artery aneurysm morphology and risk factors for aneurysm formation. J Neurosurg 2017;127:89-95 CrossRef Medline

19. van Raamt AF, Mali WP, van Laar PJ, et al. The fetal variant of the circle of Willis and its influence on the cerebral collateral circulation. Cerebrovasc Dis 2006;22:217-24 CrossRef Medline

20. De Monyé C, Dippel DW, Siepman TA, et al. Is a fetal origin of the posterior cerebral artery a risk factor for TIA or ischemic stroke? A study with 16-multidetector-row CT angiography. J Neurol 2008; 255:239-45 CrossRef Medline

21. Krabbe-Hartkamp MJ, van der Grond J, de Leeuw FE, et al. Circle of Willis: morphologic variation on three-dimensional time-of-flight MR angiograms. Radiology 1998;207:103-11 CrossRef Medline

22. Chunming L, Chenyang X, Changfeng G, et al. Level set evolution without re-initialization: a new variational formulation. Proceedings of the 2005 Institute of Electrical and Electronics Engineers Computer Society Conference on Computer Vision and Pattern Recognition, San Diego, California. June 20-26, 2005;1:430-36

23. Lieber BB, Stancampiano AP, Wakhloo AK. Alteration of hemodynamics in aneurysm models by stenting: influence of stent porosity. Ann Biomed Eng 1997;25:460 - 69 CrossRef Medline

24. Patti J, Viñuela F, Chien A. Distinct trends of pulsatility found at the necks of ruptured and unruptured aneurysms. J Neurointerv Surg 2014;6:103-07 CrossRef Medline

25. Ford MD, Alperin N, Lee SH, et al. Characterization of volumetric flow rate waveforms in the normal internal carotid and vertebral arteries. Physiol Meas 2005;26:477-88 CrossRef Medline

26. Cebral JR, Castro MA, Putman CM, et al. Flow-area relationship in internal carotid and vertebral arteries. Physiol Meas 2008;29:585-94 CrossRef Medline

27. Wåhlin A, Ambarki K, Birgander R, et al. Measuring pulsatile flow in cerebral arteries using $4 \mathrm{D}$ phase-contrast MR imaging. AJNR Am J Neuroradiol 2013;34:1740-45 CrossRef Medline

28. Thierfelder KM, Baumann AB, Sommer WH, et al. Vertebral artery hypoplasia: frequency and effect on cerebellar blood flow characteristics. Stroke 2014;45:1363-68 CrossRef Medline

29. Hendrikse J, van Raamt AF, van der Graaf Y, et al. Distribution of cerebral blood flow in the circle of Willis. Radiology 2005;235: 184-89 CrossRef Medline

30. Cebral JR, Hernandez M, Frangi A, et al. Subject-specific modeling of intracranial aneurysms. In: Proceedings of the Annual Meeting of the International Society for Optics and Photonics Symposium on Electronic Imaging, San Diego, California. February 14-19, 2004;5369:319-27 CrossRef

31. Schneiders JJ, Ferns SP, van Ooij P, et al. Comparison of phasecontrast MR imaging and endovascular sonography for intracranial blood flow velocity measurements. AJNR Am J Neuroradiol 2012;33:1786-90 CrossRef Medline

32. Xiang J, Siddiqui AH, Meng $H$. The effect of inlet waveforms on computational hemodynamics of patient-specific intracranial aneurysms. J Biomech 2014;47:3882-90 CrossRef Medline 